\title{
MATERIALISMO HISTÓRICO, CULTURA E EDUCAÇÃO: GRAMSCI, THOMPSON E WILLIAMS
}

\author{
Angela Maria Souza Martins \\ NEPHEB - HISTEDBR- UNIRIO \\ Lúcia Maria Wanderley Neves \\ Coletivo de Estudos de Política Educacional - CNPq - UFJF
}

\section{RESUMO}

Este artigo destaca pontos de confluência das contribuições de Antonio Gramsci, Edward Palmer Thompson e Raymond Williams para romper com a tradição do materialismo histórico, denominada por eles, respectivamente, de materialismo economicista, marxismo idealista e materialismo mecânico. Ao recuperar a historicidade do materialismo histórico no século XX, os três autores ampliam as noções de cultura e de educação, atribuindo-lhes um papel estratégico nos processos de dominação de classe, de transformação social e de emancipação humana.

Palavras-chave: materialismo histórico; cultura; educação; Gramsci, Thompson e Williams.

\section{HISTORICAL MATERIALISM, CULTURE AND EDUCATION: GRAMSCI, THOMPSON AND WILLIAMS}

\begin{abstract}
This article points out convergence items in the contributions of Antonio Gramsci, Edward Palmer Thompson and Raymond Williams to break with the tradition of historical materialism which they call, respectively, economicist materialism, idealist marxism, and mechanical materialism. By recuperating the historicity of 20th century historical materialism, the three authors expand the notions of culture and education and attribute them a strategic role in the processes of class domination, social transformation and human emancipation.
\end{abstract}

Keywords: historical materialism; culture; education; Gramsci, Thompson and Williams.

\section{Introdução}

Antonio Gramsci, Edward Palmer Thompson e Raymond Williams questionaram as interpretações mundialmente dominantes do materialismo histórico em boa parte do século XX e apresentaram, juntamente com outros autores (MATTOS, 2012), contribuições significativas para a recuperação da historicidade no interior do materialismo. Eles combateram com veemência o que denominaram, respectivamente, de materialismo economicista, marxismo idealista e materialismo mecânico ${ }^{1}$. Apresentaram, ainda, como denominador comum das suas reflexões teóricas, a atribuição à cultura e à educação de um papel fundamental nos processos de conservação e de transformação das sociedades contemporâneas.

As contribuições de Gramsci (1891-1937) expressaram a realidade italiana e mundial nas primeiras décadas do século XX. O pensador sardo, que construiu uma teoria marxista de política (HOBSBAWM, 2011, p. 287), estudou Letras na universidade de 
Turim, exerceu a profissão de jornalista, contribuindo para a formação da classe operária na Itália. Pertenceu ao Partido Socialista e, posteriormente, participou da fundação do Partido Comunista em seu país. Nos Cadernos do cárcere ${ }^{2}$, Gramsci mostrou como era infértil a redução do materialismo histórico ao economicismo, pois considerava o economicismo uma espécie de 'teologia', 'doutrina'. Para ele,

a pretensão (apresentada como postulado essencial do materialismo histórico) de apresentar e expor qualquer flutuação da política e da ideologia como uma expressão imediata da infraestrutura [deveria] ser combatida, teoricamente, como um infantilismo primitivo, ou [deveria] ser combatida, praticamente, com o testemunho autêntico de Marx, escritor de obras políticas e históricas concretas (GRAMSCI, 1999, p. 238).

Mostrou ainda que a estrutura econômica não deveria ser vista como algo imóvel e absoluto, mas como realidade em movimento, e que as superestruturas, as formas de consciência dos homens estariam íntima e intrinsecamente ligadas à estrutura numa relação de reciprocidade. Esta reciprocidade não poderia ser esquecida quando os homens elaboram as suas representações, normas de conduta e valores. Desse modo, estrutura e superestrutura formariam um bloco histórico. De sua vivência no interior de um determinado bloco histórico, os homens vão construindo, dialeticamente, suas explicações e justificativas do mundo, estabelecendo práticas culturais.

Já as contribuições de Thompson e Williams expressaram a realidade inglesa e mundial da segunda metade do século passado. Thompson (1924-1993), historiador e militante político, rompeu, na década de 1950, com o Partido Comunista Inglês, por discordar do que ele designou de marxismo stalinista. A partir de então, integrou-se ao movimento denominado de Nova Esquerda ${ }^{3}$, do qual também participava Williams. Ele foi tutor, entre 1948 e 1965, em cursos de educação de adultos, no Departamento de Educação Extramuros da Universidade de Leeds. Parte desses cursos era proveniente de convênios com a Associação Educacional de Trabalhadores (em inglês, Worker's Educational Association - WEA) (MATTOS, 2012). Esta atividade colocou Thompson em contato com as diferentes experiências vividas pelos trabalhadores e contribuiu para que ele percebesse que um processo revolucionário precisava provocar várias rupturas: econômica, política, nos costumes e códigos morais, o que levaria a uma mudança na consciência de classe. Thompson procurou entender como se estabeleciam as redes de significados e a percepção de padrões culturais; como eram tecidas as relações sociais e como se formavam os valores e concepções sociais. Estes três aspectos foram fundamentais para compreender a cultura tanto como modo de vida quanto como força motriz na construção da hegemonia numa determinada formação social.

Williams (1921-1988), por sua vez, foi teórico literário e também professor de Jovens e Adultos, como Thompson. Preocupado em fazer uma reavaliação do papel das práticas culturais no marxismo, colocou na sua teoria marxista de cultura a atividade humana como força primordial na construção e transformação de uma formação social e histórica. Segundo ele, há uma vinculação indissolúvel entre produção material, instituições, atividades políticas e culturais e a consciência, não sendo possível separar consciência de produção material. Existe entre essas dimensões do ser social uma relação dialética.

Com o intuito de recuperar a historicidade no interior do materialismo, esses autores confluíram para o entendimento da história como processo, da cultura como constituinte do ser social, da hegemonia como expressão de dominação de classe e da educação como uma manifestação cultural. 
Este artigo tem por finalidade apresentar elementos desse novo olhar sobre o materialismo histórico, que permitiram a Gramsci, Thompson e Williams realizar uma reinterpretação da natureza da cultura e da educação no mundo contemporâneo.

\section{Um novo olhar sobre o materialismo histórico}

Ao se insurgirem contra as concepções dominantes do materialismo histórico à época, Gramsci, Thompson e Williams retomaram as críticas de Marx e Engels às ideias materialistas do século XIX que separavam os objetos dos sujeitos e desconsideravam a ação subjetiva. Ao mesmo tempo, questionaram os fundamentos da tradição estruturalista do marxismo predominante no século XX e atribuíram um novo significado a aspectos fundamentais da estrutura e da dinâmica do ser social na contemporaneidade, como a relação entre estrutura e superestrutura, a formação das classes sociais e da consciência social e os processos contemporâneos de dominação.

Gramsci, Thompson e Williams consideraram as atividades humanas cruciais para a compreensão da estrutura e a dinâmica do ser social na sociedade capitalista. Para Gramsci, os homens são fruto das relações sociais e estão num constante devir, ou seja, eles se transformam continuamente, com as transformações das relações sociais (GRAMSCI, 1999). Os homens expressam o conjunto de suas condições efetivas de vida e existe uma relação ativa entre elementos subjetivos e objetivos (GRAMSCI, 1999). Por isso, o processo de transformação dos homens e das condições sociais implica mudanças substanciais de elementos subjetivos e objetivos. Segundo Gramsci,

é uma ilusão supor que o "melhoramento" ético seja puramente individual: a síntese dos elementos constitutivos da individualidade é "individual", mas ela não se realiza e desenvolve sem uma atividade para fora, transformadora das relações externas, desde aquelas com a natureza e com os outros homens em vários níveis, nos diversos círculos em que se vive, até a relação máxima, que abarca todo o gênero humano" (GRAMSCI, 1999, p. 406).

Assim, o subjetivo e o objetivo, o espiritual e o material se relacionam dialeticamente. O homem também é concebido por Gramsci como um bloco histórico que congrega elementos subjetivos e objetivos, que se relacionam ativa e dialeticamente, ele é um processo (GRAMSCI, 1999). Este homem ativo e contraditório contribui com suas atividades para transformar ou conservar um contexto social e histórico e também estabelece normas e regras de conduta e vida (GRAMSCI, 2000b).

Ao conceber uma formação social como bloco histórico, Gramsci (1999) enfatiza que

as superestruturas são uma realidade (...) objetiva e operante (...) a própria filosofia da práxis é uma superestrutura, é o terreno no qual determinados grupos sociais tomam consciência do próprio ser social, da própria força, das próprias tarefas, do próprio devir (GRAMSCI, 1999, p. 388).

As relações de produção, as questões políticas, os elementos socioculturais existentes num determinado contexto histórico são fundamentais para a constituição de uma formação social. Desse modo, não existe uma relação de determinação e, sim, de reciprocidade dialética entre estrutura e superestrutura.

Numa formação social há uma interação dialética constante entre as relações sociais e as atividades humanas que promovem mudanças significativas. Assim, na história, os homens constituem experiências de classe e, por meio da luta de classes, definem o seu lugar na sociedade. No embate da luta de classes, além das questões econômicas e políticas, também se estabelecem ideias, valores, normas e sentimentos que são 
fundamentais para a constituição de uma formação histórica e social. Segundo Gramsci, "o homem inteiro é modificado na medida em que são modificados seus sentimentos, suas concepções e as relações das quais o homem é a expressão necessária" (GRAMSCI, 2002 b, p. 35). Desse modo, a luta econômica não pode ser desvinculada da luta política e ideológica, até porque a supremacia de um determinado grupo social se efetiva como domínio e direção intelectual e moral.

Por isso, as atividades humanas que compõem as atividades culturais devem ser vistas como forças produtivas. As atividades culturais constituem ações no campo político e social que são imprescindíveis para a construção da hegemonia de uma determinada classe social. Qualquer classe social precisa de um arcabouço de ideias, valores e normas bem articulados para promover o consenso e construir a hegemonia. De acordo com Gramsci, as formas de dominação se efetivam não apenas por ações econômicas e políticas de modo coercitivo; o consenso construído por mecanismos ideológicos é imprescindível para a classe dominante, pois, com esses mecanismos, ela apresenta seu projeto de sociedade e sua visão de mundo como se fossem verdadeiros e universais.

Hegemonia implica consenso e direção; ela é simultaneamente ético-política e econômica. As atividades culturais instituem ações políticas, sociais e econômicas e são por estas instituídas. Por isso, para compreendermos as formações sociais contemporâneas é necessário entender a natureza da cultura, porque ela é fundamental para a consolidação da vida material e também para a instauração de um projeto societário.

Thompson, assim como Gramsci, traz as atividades humanas para o cerne do materialismo histórico e instaura o materialismo humanista, de modo que as experiências humanas tornam-se fundamentais para a formação das classes e de sua consciência. As experiências humanas decorrem das lutas travadas entre as classes sociais, são determinadas pelas condições materiais de existência.

Ele lembra ainda que Marx revelou nos Grundisse que,

em todas as formas de sociedade, é uma determinada produção e suas relações que atribuem posição e influência a qualquer outra produção e suas relações. É uma iluminação geral, em que são imersas todas as cores e que modifica suas tonalidades particulares. É um éter especial a definir a gravidade específica de tudo o que dele se destaca (MARX apud THOMPSON, 2001, p. 254).

Esta afirmação de Marx mostra que a produção econômica e suas relações são simultâneas às demais produções sociais e não determinam de modo absoluto as diferentes produções e relações sociais, apenas as condicionam.

O materialismo histórico precisa se ocupar de outros aspectos que estão além da economia, como: poder, ideologia, formação de consciência social, entre outros aspectos que possuem uma lógica diferente, porque a análise histórica "está imersa em situações em que todos os sistemas funcionam conjuntamente e todos os circuitos se intercomunicam" (THOMPSON, 1981, p. 81). Existe uma interação recíproca entre estrutura e superestrutura. Num determinado contexto histórico e social, as determinações materiais estão articuladas aos elementos subjetivos. As mudanças nas relações produtivas repercutem nas ideias e valores humanos, por isso são efetivadas na vida social e cultural.

Além disso, Thompson lembra que o objeto central da teoria marxista é o ser humano real, em todas as suas manifestações passadas e presentes. Por isso, as categorias e conceitos empregados pelo materialismo histórico somente podem ser compreendidos como categorias históricas que são importantes para investigar processos. Para a investigação histórica, a experiência é fundamental, caso se queira compreender o processo histórico como expressão da prática humana. A experiência é 
um termo médio necessário entre o ser social e a consciência social: é a experiência (muitas vezes a experiência de classe) que dá cor à cultura, aos valores e ao pensamento: é por meio da experiência que o modo de produção exerce uma pressão determinante sobre outras atividades: e é pela prática que a produção é mantida (THOMPSON, 1981, p. 112).

Assim, de acordo com Thompson, homens e mulheres experimentam situações e relações produtivas determinadas, fruto de necessidades, interesses e antagonismos, e estas experiências estão presentes em sua consciência e sua cultura do modo mais complexo possível e os fazem agir numa situação determinada (THOMPSON, 1981).

A classe se constitui com resultado de experiências comuns herdadas ou compartilhadas que, articuladas, criam a identidade de um determinado grupo social que se confronta com outro grupo social que possui interesses diferentes, ou seja, a classe nasce das relações humanas em confronto num período histórico específico. Segundo Thompson (2004),

a consciência de classe é a forma como essas experiências são tratadas em termos culturais: encarnadas em tradições, sistemas de valores, ideias e formas institucionais. Se a experiência aparece como determinada, o mesmo não ocorre com a consciência de classe (THOMPSON, 2004, p. $10)$.

Essas considerações são fundamentais para compreender como se constitui a consciência de classe. Ela nasce da articulação de valores herdados e do embate das lutas de classe (MATTOS, 2012). Precisa-se entender a heterogeneidade das classes, os processos históricos específicos de formação e conflito entre elas, seus ambientes de sociabilidade, a necessidade de uso de conceitos e métodos de outras ciências sociais como cultura, tradição e costumes no interior do processo histórico (MATTOS, 2012) para captarmos a constituição da consciência de classe. A constituição da consciência de classe somente pode ser compreendida a partir da categoria experiência; a partir das experiências das diferentes classes sociais vão se constituindo estratégias e mecanismos entre os dominantes e dominados no processo de luta de classes. A experiência é constituinte da cultura, é fundamental para compreender o processo de hegemonia, tanto que Thompson revela que nesse processo se instaura uma hegemonia cultural. De acordo com Mattos (2012), a

\begin{abstract}
"hegemonia cultural" refere-se ao fato de que o exercício da dominação de classes não se assentava primordialmente no poder econômico direto em sua forma mercantil/capitalista mais desenvolvida, nem tampouco num domínio físico ou militar mais coercitivo. O que não significava dizer que tal dominação fosse, para Thompson, "imaterial, demasiado frágil para análise, insubstancial” (THOMPSON, 1998, p. 46). Pelo contrário, tratava-se de tentar compreender o exercício do poder de classe: nas imagens de poder e autoridade, nas mentalidades populares de subordinação (MATTOS, 2012, p. 197-198).
\end{abstract}

Para compreender o processo hegemônico precisa-se considerar que as classes fazem e refazem sua cultura a partir de experiências vividas por elas. No embate entre as classes, num determinado contexto social e histórico, são criados valores, normas e princípios que entram em confronto, e os dominantes, mediante diferentes estratégias e mecanismos, vão consolidando a hegemonia. Desta forma, a cultura tem um papel preponderante para compreender os mecanismos de manutenção ou não de uma hegemonia, e a educação é parte inerente da instituição da cultura. 
Williams, assim como Gramsci e Thompson, considerou o materialismo histórico como um conjunto de reflexões em movimento e criticou a visão determinista da relação estrutura e superestrutura. Ele observou que se deve priorizar o que é dinâmico e processual na relação entre estrutura e superestrutura. Segundo este autor,

a força da crítica original de Marx se voltava principalmente contra a separação das áreas de pensamento e atividade (como na separação entre consciência e a produção material) e contra o esvaziamento correlato do conteúdo específico - atividades humanas reais - pela imposição de categorias abstratas. A abstração comum da infraestrutura e da superestrutura é, portanto, uma continuação radical dos modos de pensamento que ele atacou (WILLIAMS, 1979, p. 82, grifo do autor).

Em sua análise, teoria e prática estavam articuladas, de modo que a teoria não se desconectasse da 'vida real', porque é necessário conhecer os processos reais e específicos de cada contexto histórico. Existem vínculos indissolúveis "entre produção material, instituições e atividades políticas e culturais e consciência" (WILLIAMS, 1979, p. 84). As forças produtivas, as condições econômicas, o regime sociopolítico, a psique humana e as ideologias são indissociáveis, porque são atividades e produtos de homens reais. Por isso, a estrutura não é uma base fixa e imutável de relações e forças de produção que inexoravelmente determina a superestrutura e esta não é simplesmente um reflexo da estrutura. É preciso compreender os processos reais que se efetivam nas relações sociais num contexto histórico específico. A estrutura não pode ser considerada como um conjunto de abstrações econômicas e tecnológicas, porque ela expressa relações sociais e econômicas reais, que contêm contradições (WILLIAMS, 2011).

Segundo Williams, Marx mostrou que historicamente existem

contradições profundas entre as relações de produção e as consequentes relações sociais. Há portanto a possibilidade permanente de variação dinâmica dessas forças (...). Só quando compreendemos que "a base", com a qual é comum relacionar as variações, é em si mesma um processo dinâmico e internamente contraditório - as atividades específicas e os modos de atividade, que vão de associação a antagonismo, dos homens reais e de classes de homens - que podemos começar a nos libertarmos da noção de uma "área" ou "categoria" dotada de certas propriedades fixas para dedução dos processos variáveis de "superestrutura" (WILLIAMS, 1979, p. 86).

Williams, ao se distanciar do uso estanque da metáfora estrutura e superestrutura, busca compreender as especificidades da materialidade que constituem as questões culturais. Ele mostra que em todas as sociedades e períodos históricos existem práticas, significados e valores que são instituídos e vividos, por isso é preciso compreender o processo social real de onde a cultura emerge.

No processo de construção da hegemonia, uma determinada classe social entrelaça valores, práticas e significados que são incorporados na cultura e na ordem social efetiva. A hegemonia é um processo dinâmico, porque uma sociedade é um todo complexo de práticas e também tem uma organização e estrutura específica, porém os princípios dessa organização e estrutura expressam intenções sociais regidas por uma determinada classe. De acordo com Williams,

[as] leis, constituições, teorias e ideologias que são tão frequentemente defendidas como naturais ou como tendo validade ou significância universal devem ser vistas como simplesmente expressando e ratificando a dominação de uma classe particular. (...) Podemos usar corretamente a 
noção de totalidade apenas quando a combinamos com o conceito marxista crucial de "hegemonia" (WILLIAMS, 2011, p. 51).

A hegemonia implica totalidade e dominação, mas também a possibilidade de mudança, porque, de acordo com Williams, as estruturas internas do processo hegemônico são complexas e podem ser renovadas, recriadas e desafiadas (WILLIAMS, 2011). Como a hegemonia não é uma construção estática, uma cultura dominante somente pode ser compreendida no processo social real onde ela está incorporada. Nas instituições educacionais e também nas outras instâncias culturais estão incorporados valores e ideias que a classe dominante enfatiza e seleciona, mas paralelamente existem significados e práticas que são negligenciados e excluídos desse processo. Há experiências, práticas, significados e valores, que não fazem parte da cultura dominante, que podem fazer oposição a esta cultura, mas esta oposição depende da correlação de forças sociais. Os processos de formação social na família, na educação, as definições no processo de trabalho, o modo como a classe dominante seleciona no plano intelectual e teórico suas diretrizes, todas essas forças estão num processo contínuo de fazer e refazer uma cultura dominante, e são imprescindíveis para a construção da hegemonia.

Deve-se compreender a cultura como prática social, ou seja, modo de ser e de viver, por isso ela é um espaço fundamental para a luta política e para a dominação. As práticas culturais são fundamentais para a consolidação da hegemonia. De acordo com Williams, "a consciência não mais é o mero produto do ser social, mas é ao mesmo tempo uma condição da sua existência prática e, ainda, uma de suas forças produtivas centrais" (WILLIAMS, 2011, p. 349). Por isso, as transformações no modo de produção não podem ocorrer apenas nas relações de produção; devem também acontecer nas forças de produção que são simultaneamente manuais e intelectuais. Assim, é necessário transformar as relações de produção e as forças produtivas.

Williams defende que, no processo de transformação estrutural de uma sociedade, é preciso uma mudança no modo de ser e viver, porque

a consciência, a individualidade, a própria ordem social, são então vistas como subprodutos da produção necessária (...) A revolução cultural insiste, primeiramente, que o que a sociedade necessita produzir, antes de tudo, é o maior número possível de indivíduos conscientes, capazes de todas as associações necessárias (WILLIAMS, 2011, p. 366).

(...) Uma tarefa central da revolução cultural, em sua alteração imperiosa da natureza das forças produtivas, é uma redefinição prática da natureza das forças produtivas, é uma redefinição prática da natureza do "trabalho" (WILLIAMS, 2011 p. 366-367).

Esta tarefa é imprescindível no processo de formação e da tomada de consciência de uma nova classe e na construção de uma contra-hegemonia. Mas Williams nos lembra que a hegemonia deve ser considerada sempre como processo, porque é um complexo de experiências, relações e atividades, com pressões e limites específicos e mutáveis.

Assim, é necessário compreender que a sociedade capitalista gera significados e valores que precisam ser enfrentados e derrotados por meio de um trabalho intelectual e educacional contínuo. A educação e a comunicação são tão fundamentais quanto os sistemas político e econômico. A cultura é um espaço de dominação, pois ações no campo da cultura afetam o modo de vida e consolidam determinados princípios e valores que podem perpetuar todo um processo de direção e domínio. Por isso precisa-se

aprender e ensinar uns aos outros as conexões que existem entre uma formação política e uma econômica, e, talvez, o mais difícil, uma 
formação educacional e uma de sentimentos e de relações que são nossos recursos mais imediatos em qualquer forma de luta (WILLIAMS apud CEVASCO, 2001, p. 137).

Com Williams aprende-se que um processo hegemônico não resulta apenas de uma ideologia bem-articulada que exerce a manipulação e a doutrinação. Na verdade, ele decorre de um conjunto de práticas e expectativas sobre a totalidade da vida.

Em síntese, este novo olhar sobre o materialismo histórico na contemporaneidade se constitui em arcabouço teórico-metodológico para as reflexões desses autores sobre cultura e educação.

\section{Um conceito ampliado de cultura}

Gramsci não teorizou especificamente sobre a noção de cultura. Ele a traz da perspectiva antropológica e a adota como pressuposto fundamental de suas reflexões no cárcere sobre as relações de poder no capitalismo monopolista e, principalmente, sobre as novas formas de dominação de classe que se constituíram com o desenvolvimento de uma nova cultura ${ }^{4}$.

Cultura foi por ele entendida como "modo de viver, de pensar e de operar" ou "modo de ser e de viver" (GRAMSCI, 1999, p. 258-259) de uma sociedade, no desenvolvimento do processo histórico. Como pensador e militante político, Gramsci estava preocupado em identificar as estratégias utilizadas pelas várias frações da classe dominante para obter o consentimento ativo ou passivo do conjunto da sociedade à sua concepção de mundo, ao seu projeto político e às formulações e práticas culturais e políticas que contribuíssem para a efetivação de uma reforma intelectual e moral das classes trabalhadoras rumo a uma sociedade socialista.

Ele percebeu com sagacidade e antecipação que estava em curso um processo de formação de uma nova cultura - de natureza urbano-industrial - oriunda das profundas mudanças na produção da vida nos anos iniciais do século XX nos Estados Unidos. Na sua concepção, este novo modo de pensar, sentir e agir era apenas um momento inicial de um processo que se estenderia a todo o mundo contemporâneo.

Para Gramsci, portanto, se impunha como tarefa revolucionária assimilar, na reflexão e na militância política, os elementos da nova cultura emergente de modo a tornar a classe trabalhadora mais conforme ao seu tempo e, de forma simultânea, apta a construir coletivamente novas relações sociais de natureza mais humana e igualitária. Era, portanto, necessário criar as condições de desenvolvimento de uma nova cultura. Mais explicitamente, ele considerava que "deve[r]-se[ia] falar de luta por uma nova cultura, isto é, por uma nova vida moral, que não pode[ria] deixar de ser intimamente ligada a uma nova intuição da vida, até que esta se torn[ass]e um novo modo de sentir e de ver a realidade (...)" (GRAMSCI, 2002a, p. 70). Nessa perspectiva, a produção intelectual e manifestações artísticas se configurariam como importantes elementos constituidores dessa elaboração complexa.

No seu entendimento, a organização de uma nova cultura requer, principalmente, a difusão de verdades já descobertas para transformá-las em base de ações vitais e, também, a realização individual de descobertas originais. A cultura urbano-industrial em formação, portanto, demandava das classes dominantes e das classes dominadas o desenvolvimento de novas tarefas educadoras na construção e consolidação da hegemonia e da contrahegemonia cultural e política. Nessa tarefa de organização da cultura urbano-industrial nascente desempenhavam papel estratégico na sociedade civil os aparelhos culturais e políticos de hegemonia, entre eles as igrejas, as escolas, os jornais e revistas, as 
associações e os partidos. Os intelectuais, nesse novo contexto histórico, numericamente ampliados, desempenhariam, individual e coletivamente, o papel de organizadores da cultura dominante e da cultura dominada em luta.

$\mathrm{Na}$ formação dessa nova cultura na ótica do trabalho, foco das reflexões de Gramsci, seria imprescindível transformar a 'mentalidade' popular e difundir fundamentos filosóficos que se transformassem em substrato do agir humano nas sociedades socialistas, o que incluiria necessariamente um programa de reforma econômica. Ele chega a afirmar, neste sentido, que a "reforma econômica é exatamente o modo concreto através do qual se apresenta toda reforma intelectual e moral" (GRAMSCI, 2000b, p. 19). Com esta observação, Gramsci reforça a sua concepção dialética da relação entre infraestrutura e superestrutura, na qual essas duas dimensões do ser social, ao constituírem uma unidade entre conteúdo e forma, entre o pensar, o agir e o sentir, formam um bloco histórico.

Tal como Gramsci e influenciado pela leitura do pensador sardo, Thompson, apesar de não ter como objeto de estudo a elaboração de uma teoria da cultura, incorpora entre as suas reflexões sobre o socialismo humanista ou humanismo socialista e, mais especificamente, sobre a formação da classe operária inglesa, os elementos culturais como propulsores da dinâmica social.

Thompson entende cultura como um sistema de atitudes, valores e significados compartilhados e as formas simbólicas em que se acham incorporados (THOMPSON, 1998). Mas destaca que, por reunir várias "atividades e atributos em um só feixe", o termo 'cultura' pode confundir ou ocultar distinções da realidade que só seriam apreendidas por meio da análise cuidadosa de seus componentes (THOMPSON, 1998, p. 22). Resguardando-se de uma interpretação ultraconsensual desta noção, realça que a cultura é "uma arena de elementos conflitivos, que somente sob uma pressão imperiosa - por exemplo, o nacionalismo, a consciência de classe ou a ortodoxia religiosa predominante assume a forma de "sistema"' (THOMPSON, 1998, p. 17).

Essa ênfase nas contradições e lutas, que Thompson imprime à análise que faz da cultura das formações sociais contemporâneas, leva esse autor a abordar, de forma direta e precisa, a relação entre cultura e classe como processos histórico-sociais indissociáveis (MATTOS, 2012), já que para ele

\begin{abstract}
a classe se delineia segundo o modo como os homens e mulheres vivem suas relações de produção e segundo a experiência de suas situações determinadas, no interior do "conjunto de suas relações sociais", com a cultura e as expectativas a eles transmitidas e com base no modo pelo qual se valeram dessas experiências em nível cultural (THOMPSON, 2001, p. 277, grifos do autor).
\end{abstract}

Esta afirmação ajuda-nos a compreender o sentido que Thompson nos oferece ao intercurso dialético entre cultura e não-cultura. Novamente com Gramsci, ele observa ainda que, nas relações entre o ser social e a consciência social nas sociedades classistas, há uma organização cognitiva da vida que correspondente, necessariamente ao modo de produção material da existência. Realiza-se, dessa forma, na história, uma junção entre experiência e cultura, uma vez que as pessoas experimentam a própria experiência como ideias, "no âmbito do pensamento e de seus procedimentos" e "como sentimento, assim como lidam com esses sentimentos na cultura, como normas, obrigações, valores, na arte e nas convicções religiosas" (THOMPSON, 1981, p. 189).

Para Thompson, não se pode falar de classe "sem que as pessoas, diante de outros grupos, por meio de um processo de luta, entrem em relação de oposição sob uma forma classista, ou ainda sem que modifiquem as relações herdadas, já existentes" (THOMPSON, 2001, p. 275). Na formulação thompsiana, portanto, nem a formação de classe pode ser 
independente de determinações objetivas nem a classe pode ser definida apenas como um fenômeno cultural.

Essa dimensão da totalidade histórica na compreensão da dinâmica dos processos sociais faz com que Thompson conclua, em relação aos processos históricos de transformação social, que "não só o socialismo, mas qualquer futuro feito pelos homens e mulheres" se baseia na ciência, nas determinações da necessidade e também "numa escolha de valores e nas lutas para tornar efetivas essas escolhas" (THOMPSON, 1981, p. 212).

Tal como Gramsci e Williams, Thompson concebe a cultura no sentido amplo, como modo de vida, como modo de luta e, também, no sentido restrito, como produção intelectual e artística, sentidos que se encontram no mesmo caldo da vida material dos homens (MATTOS, 2012).

Diferentemente de Gramsci e Thompson, que tomam a cultura como um pressuposto fundamental de análise das sociedades capitalistas contemporâneas, a construção de uma teoria marxista de cultura torna-se o foco dos estudos teóricos de Williams ao longo de toda a sua vida acadêmica. Nesse sentido, ele desenvolve o que denominou de materialismo cultural, "uma teoria das especificidades da produção cultural e literária material, dentro do materialismo histórico" (WILLIAMS, 1979, p. 12), lançando as bases para um campo de estudos denominado de "estudos culturais". Com essa empreitada, Williams, recorrendo às descobertas de Gramsci e dialogando frequentemente com os estudos de Thompson, expande de forma sistemática o conceito de cultura, seu campo de ação e sua capacidade cognitiva (CEVASCO, 2001).

O materialismo cultural enfatiza a impossibilidade da separação entre homem estético e homem econômico, colocando a 'arte' em um extremo, e o 'trabalho' em outro (WILLIAMS apud CEVASCO, 2001, p. 54). Para Williams, com essa maneira de ver a realidade histórica, o marxismo contemporâneo estaria "reaprendendo o sentido real de totalidade" (WILLIAMS apud CEVASCO, 2001, p. 137). Sua teoria da cultura não realiza uma crítica dentro de uma tradição teórica - pois ela reconhece que o marxismo não atribuiu a devida importância à dimensão cultural dos processos sociais. Essa teoria constituiu-se em resposta a "mudanças radicais nas relações sociais de processos culturais dentro da sociedade britânica e de outras sociedades a ela compatíveis" (WILLIAMS, 2011, p. 334). Para Williams, tornou-se impossível, com o surgimento das novas formas de radiodifusão, sobretudo a televisão, e as mudanças formais na publicidade e na imprensa, "ver as questões culturais como passíveis de serem separadas de questões políticas e econômicas ou postular uma relação de segunda ordem ou de dependência entre elas", (WILLIAMS, 2011, p. 335).

Para o materialismo cultural, portanto, o sistema de aprendizagem e de comunicação é tão central quanto o sistema de decisão [o político] e o sistema de manutenção [o econômico] (WILLIAMS apud CEVASCO, 2001, p. 31) e, nesse sentido, Williams concluiu que toda sociedade é constituída e constituinte da cultura. Constatou também que a consciência é social. Seus processos ocorrem não só entre, mas também dentro da relação e do relacionado. Ou seja, toda subjetividade é também objetividade (WILLIAMS, 1979). Não há cultura descarnada dos processos materiais de produção da vida. Ser e consciência formam uma totalidade histórica.

O materialismo cultural utiliza o termo cultura numa dupla dimensão indissociável $^{6}$. Williams, a esse respeito, esclarece:

Usamos a palavra cultura nesses dois sentidos, para designar modo de vida - os significados comuns - e para designar as artes e o aprendizado - os processos especiais de descoberta e esforço criativos. Alguns críticos 
reservam esta palavra para um ou para outro desses sentidos: eu insisto nos dois e na relevância de sua conjunção (WILLIAMS apud CEVASCO, 2001, p. 118).

Duas décadas após, em Cultura (2008), Williams atualiza essas reflexões, incorporando expressões que dão conta das profundas mudanças no modo de ser das sociedades capitalistas do final do século $\mathrm{XX}$, ampliando com isso a abrangência do fenômeno cultural:

(i) os sentidos antropológico e sociológico de cultura como 'modo de vida global' distinto, dentro do qual percebe-se, hoje, um 'sistema de significações' bem definido não só como essencial, mas como essencialmente envolvido em todas as formas de atividade social, e (ii) o sentido mais especializado, ainda que também mais comum, de cultura como "atividades artísticas e intelectuais", embora estas, devido à ênfase em um sistema de significações geral, sejam agora definidas de maneira muito mais ampla, de modo a incluir não apenas as artes e as formas de produção intelectual tradicionais, mas também todas as 'práticas significativas' - desde a linguagem, passando pelas artes e filosofia, até o jornalismo, moda e publicidade - que agora constituem esse campo complexo e necessariamente extenso (WILLIAMS, 2008, p. 13).

Essa ampliação da dimensão cultural nas sociedades da segunda metade do século anterior justifica o emprego da denominação 'Era da Cultura' para as sociedades capitalistas do segundo pós-guerra e a constatação da ocorrência de uma crise da cultura contemporânea mediante as rápidas mudanças nas práticas, significados e valores nos anos iniciais do século em curso.

Os pressupostos teóricos do materialismo cultural possibilitaram que Williams percebesse a cultura como ordinária, comum e potencialmente transformadora. Rompendo com o conceito elitista de cultura, que a concebe como "um domínio separado da esfera do cotidiano, um espaço único onde se produzem as grandes obras da humanidade", o materialismo cultural afirma a cultura como ordinária, comum a todos, inerente ao nosso modo de vida, um processo que acontece em vários níveis, do qual todos participam (CEVASCO, 2001, p. 47). Cevasco destaca o profundo senso de igualdade presente na constatação de Williams. Nessa constatação, está embutida a ideia de que toda sociedade humana tem a sua própria forma, seus próprios propósitos e seus significados e também a de que "a teoria da cultura pode ser definida como o estudo das relações entre os elementos de todo um modo de vida" ( WILLIAMS apud CEVASCO, 2001, p. 50).

Embora esse profundo senso de igualdade esteja contido nas suas reflexões sobre cultura, Williams não deixa de destacar que em qualquer sociedade e em qualquer período específico há um sistema central de práticas, significados e valores organizados e vividos que aparecem confirmando-se mutuamente e que são incorporados pela maioria das sociedades como cultura dominante.

Todavia, observa também que a cultura dominante "nunca, na realidade inclui ou esgota toda a prática humana, toda energia humana" (WILLIAMS, 1979, p.128). Ocorrem, simultaneamente, práticas culturais e sociais alternativas e opositoras, residuais e emergentes. As práticas alternativas e opositoras distinguem-se teoricamente. Nas primeiras, incluem-se as práticas simplesmente diferentes daquelas dominantes. Nas últimas, incluem-se as práticas que querem mudar a sociedade. Por sua vez, as práticas residuais expressam uma faceta remanescente de formações sociais anteriores, facilmente incorporadas às práticas dominantes. As emergentes, por sua vez, brotam dos novos significados e valores, sentidos e experiências continuamente criados na cultura 
contemporânea efetiva e que a classe dominante tenta incessantemente incorporá-los. Em resumo, pode-se afirmar que, para Williams, conservação e mudança, de forma dinâmica, disputam a hegemonia cultural e social em cada momento específico do modo de vida.

Assim como Gramsci e Thompson, Williams, na sua teoria de cultura, analisando a complexidade dos processos sociais específicos das sociedades capitalistas do século XX, advoga a possibilidade concreta de transformação social.

Ele acredita que o sistema de significados e valores que a sociedade capitalista gera tem que ser derrotado no geral e no detalhe através de um trabalho intelectual e educacional contínuo, o que o aproxima da ideia gramsciana de uma necessária reforma intelectual e moral, para romper com a hegemonia cultural e política da burguesia na contemporaneidade. Assim como Gramsci, Williams tinha a clareza de que a revolução cultural ocorre concomitantemente à revolução democrática e industrial. A esse processo abrangente, dirigente e educador da revolução processual, em Gramsci, Williams denominava de revolução longa.

Temos [os socialistas] que aprender a ensinar uns aos outros as conexões que existem entre uma formação política e uma econômica, e, talvez, a mais difícil, uma formação educacional e uma de sentimentos e de relações que são nossos recursos mais imediatos em qualquer forma de luta (WILLIAMS apud CEVASCO, 2001, p. 137).

Nessa aprendizagem de estratégias de superação do antagonismo de classes e de criação de uma cultura em comum, estar-se-ia superando de forma radical o velho problema das relações entre interesses específicos e o interesse geral.

Uma revolução cultural teria como principal impulso a educação política dos vários grupos necessários para dar-lhe substância e torná-la possível. Sem se referir à formação de intelectuais, como diria Gramsci, Williams propõe, como estratégia revolucionária, a formação de organizadores da nova cultura. A revolução cultural, portanto, deveria ser

orientada para a apropriação geral de todas as forças reais de produção incluindo agora, sobretudo, as forças intelectuais de conhecimento e de tomada de decisão consciente como meios necessários para revolucionar as relações sociais (...) que decorrem de formas variáveis de controle e acesso a todas as forças produtivas (WILLIAMS, 2011, p. 350).

A cultura das classes trabalhadoras encontra expressão no seu modo de vida regido por um princípio oposto ao das classes dominantes: a solidariedade. Sua maior contribuição cultural no século XX foi, sem dúvida, a criação de instituições de classe sindicatos, partidos políticos, erigidos sob uma lógica oposta à dominante na sociedade capitalista (MATTOS, 2012). Na Era da Cultura em crise, nestes anos iniciais do século $\mathrm{XXI}$, os valores e instituições das classes trabalhadoras parecem entrar em um processo rápido de mudança cujos contornos se encontram em fase de delineamento.

O reconhecimento de que a sociedade é constituída e constituinte da cultura, assim como o reconhecimento do potencial transformador das práticas culturais fizeram com que Williams, em consonância com Gramsci e Thompson, desse aos processos educacionais e pedagógicos relevância estratégica na construção do socialismo.

\section{Educação política e educação escolar: um bloco histórico}

Gramsci, Thompson e Williams, cada um a seu modo, elegeram a educação como uma prática cultural e social fundamental para a sedimentação da hegemonia das classes dominantes nas sociedades capitalistas contemporâneas, mas reconheceram também o seu 
potencial criador de um ambiente cultural e político educador de uma contra-hegemonia das classes dominadas.

Assim como analisaram a cultura no sentido amplo e no sentido estrito como processo e como produto interconectados, os três autores apreenderam a prática educativa numa dupla e concomitante acepção, como educação política e como educação escolar. E, por não ser possível, na história, separar o homem econômico do homem ético e do homem estético, ambos os processos de educação política e de educação escolar incluem necessariamente determinações técnicas e ético-políticas, ou seja, intelectuais e valorativas, onde razão e sentimento, corações e mentes como um bloco histórico fundamentam o agir humano.

Gramsci afirmava que "a relação pedagógica não [poderia] ser limitada às relações especificamente 'escolares', por meio das quais as novas gerações [entrariam] em contato com as antigas e [absorveriam] suas experiências e seus valores historicamente necessários, 'amadurecendo' e desenvolvendo uma personalidade própria, histórica e culturalmente superior" (GRAMSCI, 1999, p. 399). Ele observou também que esta relação pedagógica abrangente existe em toda a sociedade e em todo indivíduo, nas relações entre sujeitos singulares e coletivos, entre governantes e governados e dirigentes e dirigidos. Por isso, pode-se inferir que

toda relação de "hegemonia" é necessariamente uma relação pedagógica, que se verifica não apenas no interior de uma nação, entre as diversas forças que a compõem, mas em todo o campo internacional e mundial, entre conjuntos de civilizações nacionais e continentais (GRAMSCI, 1999, p. 399).

No capitalismo monopolista, o Estado ${ }^{7}$ em sentido estrito e o partido na sociedade civil passaram a educar mais sistematicamente a adesão orgânica da maioria da sociedade ao projeto político da burguesia, desenvolvendo estratégias de uma pedagogia da hegemonia, que vem se metamorfoseando com a dinâmica da produção da vida. A tarefa revolucionária que, para ele, demandava uma efetiva reforma intelectual e moral de cada indivíduo e de toda a sociedade exigia o desenvolvimento de estratégias de uma contrahegemonia, por parte do bloco histórico das forças sociais comprometidas com a construção de novas relações societais.

A escola, em todos os níveis e modalidades, e a Igreja eram para Gramsci as duas maiores organizações culturais em todos os países, graças ao número de pessoas que utilizam $^{8}$. A escola teria por finalidade principal formar os intelectuais de diferentes níveis, organizadores da hegemonia política e cultural burguesa.

Analisando a realidade escolar do capitalismo nos anos iniciais do século XX, Gramsci verificou que esta instituição estruturava-se de forma dual ${ }^{9}$ : escolas profissionalizantes para as massas trabalhadoras e uma escola humanista clássica para as várias frações das classes dominantes. Ele propôs a superação daquele apartheid educacional, pela criação de uma escola unitária básica para todos, financiada e gerida pelo Estado, que tivesse como princípio educativo o trabalho enquanto atividade teórico-prática do homem. Gramsci rechaçava a ideia de trabalho como prática profissional, pois constatou com propriedade que a cultura urbano-industrial, de natureza científicotecnológica, propiciou o surgimento de uma relação mediatizada entre educação e produção da vida, exigindo uma nova estruturação da escola. Uma escola que propiciasse "um conhecimento exato e realista das leis naturais e da ordem legal que [regulasse] organicamente a vida dos homens entre si" (GRAMSCI, 2000a, p. 43). A escola unitária deveria ser necessariamente uma escola criadora que ensinasse o conjunto das massas trabalhadoras a pensar, a estudar, a dirigir e a controlar quem dirige. Coerente com sua 
concepção ampliada de educação, ele antevia que "o advento da escola unitária [significaria] o início de novas relações entre trabalho intelectual e trabalho industrial não apenas na escola, mas em toda a vida social" (GRAMSCI, 2000a, p. 40).

Enquanto Gramsci sistematizava suas ideias sobre educação e pedagogia no cárcere, dialogando com a proposta educacional do fascismo e da proposta liberal de educação à época (escola ativa), ou mesmo, de forma incidental, com o projeto soviético de educação, Thompson e Williams desenvolviam suas reflexões educacionais em meio às suas atividades acadêmicas e militantes.

Refletindo sobre o processo educador da socialização, Williams observou que qualquer processo de socialização inclui a aprendizagem de conhecimentos e de habilidades que todos os seres humanos devem aprender para se tornarem conformes ao seu tempo. Chamou a atenção também para o fato de que essas aprendizagens gerais se unem ao aprendizado específico de uma variação selecionada de significados, valores e práticas que constitui a base real do hegemônico. Este processo educador efetiva-se por intermédio das instituições incorporativas tais como a família, as escolas, as igrejas, as comunidades específicas e os locais específicos de trabalho e a mídia (WILLIAMS, 1971).

Para ele, as instituições educacionais são geralmente as principais agências de transmissão de uma cultura dominante eficaz. Elas incorporam a dupla e indissociável dimensão econômica e cultural da atividade humana no capitalismo monopolista.

Aliás, Williams afirmava que os sistemas de aprendizagem e de comunicação são tão centrais quanto os sistemas de decisão e de manutenção. Os meios de comunicação de massa, especialmente a televisão, na perspectiva dele, exercem um importante papel educador nas sociedades contemporâneas. Ele acreditava que esses meios se constituem em condição técnica necessária para a criação de uma cultura comum, embora, de modo realista, soubesse que, sob a hegemonia burguesa, tais meios atuam majoritariamente no sentido de cimentar a dominação cultural.

Refletindo especificamente sobre a educação escolar na Inglaterra em fase posterior àquela vivida por Gramsci na Itália, Williams já fixava o seu olhar nas barreiras que a educação escolar hegemônica interpunha ao acesso igualitário dos indivíduos à escola em todos os níveis e modalidades de ensino. Cevasco (2001) destaca que, em Culture is Ordinary, Williams, comparando as estatísticas de acesso à educação superior americanas e soviéticas com as inglesas à época, teria concluído de forma sarcástica que os ingleses deviam ter chegado tarde na fila da inteligência ${ }^{10}$.

Dentre suas propostas para a democratização cultural, Williams salientava, além do acesso igualitário ao processo de escolarização, a redefinição dos conteúdos escolares, o financiamento pela sociedade ${ }^{11}$ da produção artística e escolar e a redefinição da lógica capitalista da comunicação de massas. Tais iniciativas contribuiriam, efetivamente, para derrotar o sistema de valores e significados que a sociedade capitalista gera, uma vez que um processo revolucionário de longa duração exige um trabalho intelectual e educacional contínuo.

Para ele, portanto, uma revolução cultural deveria ser orientada para "a apropriação geral de todas as forças reais de produção, incluindo (...) as forças intelectuais de conhecimento e de tomada de decisão consciente como meios necessários para revolucionar as relações sociais" (...) (WILLIAMS, 2011, p. 350).

Tal como Gramsci e Williams, Thompson também se preocupava com o papel a ser desempenhado pela educação na construção de um projeto revolucionário. Para ele, esse projeto deveria abranger o enfrentamento de várias frentes simultâneas de ruptura e ser constituído por pressão e mobilização populares de grande intensidade, em decorrência de um amplo trabalho de educação política para elevação da consciência de classe. Tais 
pressões do processo histórico concreto estabeleceriam efetivamente o "ponto de ruptura" socialista (MATTOS, 2012). Esse entendimento do processo revolucionário norteou suas críticas ao projeto educacional vigente e à construção de seus enunciados sobre a educação de adultos.

Thompson chamou a atenção para as estratégias educacionais de dominação de classe utilizadas pelas classes dominantes desde o período da formação da classe operária inglesa. Ele afirmava que

educação e cultura, não menos que impostos locais para os pobres, eram encaradas como esmolas que deveriam ser administradas ao povo ou dele subtraídas de acordo com seus méritos. O desejo de dominar e de moldar o desenvolvimento intelectual e cultural do povo na direção de objetivos predeterminados e seguros permanece extremamente forte durante a época vitoriana: e continua vivo até hoje (THOMPSON, 2002, p. 31).

A sua crítica se dirigiu ainda à postura dos educadores da classe média que, por não conseguirem distinguir o trabalho educacional do controle social, viabilizaram por mais de um século e meio estratégias educacionais que "impunha[m] com demasiada frequência uma repressão à validade da experiência de vida dos alunos ou sua própria negação" (THOMPSON, 2002, p. 36), gerando uma dicotomia entre cultura letrada e experiência de vida no seio das classes trabalhadoras até os nossos dias.

No entanto, observou que, no decorrer do século XX, nos centros industriais, os professores, mais articulados politicamente, assumiram uma posição de defesa de uma cultura mais igualitária que vem sendo ameaçada nas últimas décadas pela maneira como vem se processando a ampliação das oportunidades educacionais decorrente das pressões dos partidos trabalhistas e das necessidades de uma sociedade industrial adiantada (THOMPSON, 2002). A educação passou a ser vista, em grande escala, também por frações das classes trabalhadoras, simplesmente como "um instrumento de mobilidade social seletiva". Um meio eficaz para o sucesso, conseguido pela "recompensa financeira, um certo estilo de vida profissional e um certo prestígio social" (THOMPSON, 2002, p. 42).

Essa nova tendência político-pedagógica que perpassa toda a escolarização também se efetiva, de modo particular, na prática docente das instituições universitárias. Embora reconheça a dificuldade de se conseguir o equilíbrio entre o rigor intelectual e o respeito à experiência, este historiador/educador reconheceu lucidamente que

a grande parte do professor universitário é do tipo de um merceeiro intelectual, pesando e avaliando currículos de cursos, lista de livros para leitura, temas para ensaios, de acordo com determinado treinamento. $\mathrm{O}$ perigo é que esse tipo de tecnologia profissional necessária seja confundida com autoridade intelectual e que as universidades apresentando-se como um sindicato de todo os "peritos" em cada ramo do conhecimento - expropriem as pessoas de sua identidade intelectual (THOMPSON, 2002, p. 43).

Em contraposição a essa nova configuração da escolarização contemporânea, Thompson propôs uma educação que, em todos os níveis e modalidades, efetuasse uma dialética necessária entre educação e experiência. Este princípio de uma educação emancipadora, construído com base em sua prática educadora de adultos trabalhadores, parte do pressuposto de que aquilo que as pessoas comuns fazem é digno de interesse e atenção. Este princípio educativo o aproxima da teorização de Williams sobre o caráter ordinário da cultura e sobre a necessidade de se construir uma cultura em comum. 
Sistematizando essa dialética entre educação e experiência na prática docente, Thompson, em consonância com princípios educativos gramscianos, trouxe elementos importantes para a reflexão sobre a prática pedagógica contemporânea:

Toda educação que faz jus a esse nome envolve a relação de mutualidade, uma dialética, e nenhum educador que se preze pensa no material a seu dispor como uma turma de passivos recipientes de educação. (...) $\mathrm{Na}$ educação liberal de adultos, nenhum mestre provavelmente sobreviverá a uma aula - e nenhuma turma provavelmente continuará no curso com ele - se ele pensar, erradamente, que a turma desempenha um papel passivo (THOMPSON, 2002, p. 13).

Não obstante Thompson tenha reconhecido a dificuldade de se conseguir o equilíbrio entre o rigor intelectual e o respeito à experiência, ele reconheceu também que este equilíbrio está hoje seriamente prejudicado, especialmente com a forte expansão da educação escolar a partir da segunda metade do século anterior. Para Thompson, as mudanças quantitativas e qualitativas no público alcançado pela educação escolar não deveria implicar alteração na mutualidade desse relacionamento. Aliás, o rompimento dessa mutualidade fez com que ele rechaçasse o emprego dos meios de educação de massas na suplementação do ensino profissional na educação de adultos.

Mesmo pontuando essas limitações recentes, ele não deixa de acreditar que as conquistas educacionais do século XX poderão se dirigir para a construção de uma cultura igualitária comum, neste século que se inicia, desde que seja mantido e ampliado o intercâmbio dialético entre educação e experiência. A democracia acontecerá por si mesma - se acontecer - em toda a nossa cultura e, para que isso aconteça, os educadores, em especial os professores universitários, precisam do contato de diferentes mundos de experiência, no qual ideias sejam trazidas para prova da vida.

\section{Considerações finais}

As contribuições de Gramsci sobre cultura e política se constituíram em fontes propulsoras determinantes para a construção do materialismo humanista de Thompson e para o materialismo cultural de Williams. Ao conceber o homem como um devir, constituído em meio às relações de classe e ao inserir a construção coletiva de uma reforma intelectual e moral entre as estratégias de transformação social, Gramsci forneceu aos marxistas ingleses elementos de crítica que buscavam para se insurgir contra o marxismo stalinista de meados do século XX, bem como ofereceu reflexões significativas para o resgate da centralidade das práticas culturais na análise dos processos societais capitalistas contemporâneos.

As contribuições dos três autores, ao se fundamentarem no princípio da dialeticidade da relação estrutura e superestrutura, ofereceram elementos de reflexão sobre a natureza indissociável da relação entre objetividade e subjetividade e entre o material e o espiritual. Tais construções teórico-metodológicas fornecem argumentos para que se possa fazer a crítica às ideias, tão em voga na atualidade, que sinalizam para a autonomia do simbólico frente ao conjunto das relações sociais.

Suas contribuições nos ajudam a superar a ideia, ainda tão presente no senso comum das sociedades contemporâneas, que relaciona cultura à erudição. Ou seja, a ideia conservadora de que somente a uns poucos 'iluminados' é dada a oportunidade de pensar, sentir e decidir. Se a cultura é comum, o ato de pensar, de sentir e de agir é de todos. Com isso, os autores demarcam dois princípios educativos fundamentais: a experiência vivida deve ser sempre o ponto de partida da ação pedagógica, e o trabalho pedagógico, em 
sentido amplo e em sentido estrito, consiste em encontrar o justo equilíbrio entre o conhecimento produzido pela humanidade e a experiência vivida pelos estudantes. Aliás, este é o sentido mais abrangente que podemos dar ao que Gramsci chamava de uma síntese entre trabalho intelectual e trabalho industrial.

Esses três autores nos fornecem, ainda, elementos significativos para o resgate da importância da reflexão crítica e processual, na construção concomitante do homem e da sociedade nos dias atuais, quando as mídias, seduzindo pela beleza da forma, relega para segundo plano o processo de construção histórica dos fenômenos sociais, privilegiando a aparência em detrimento da essência, na análise da dinâmica societal.

Em relação às práticas educativas, dois aspectos de suas elaborações teóricometodológicas nos remetem à reflexão sobre o conteúdo das propostas educacionais e das práticas pedagógicas neste século que se inicia. $\mathrm{O}$ primeiro diz respeito à afirmação da educação política e da educação escolar como uma totalidade histórica. O segundo trata da indissociabilidade entre as determinações técnicas e ético-políticas na formação humana na cultura urbano-industrial.

A indissociabilidade entre educação política e educação escolar impossibilita a ideia de uma separação entre escola e prática cultural e social. A prática escolar reproduz majoritariamente as práticas culturais dominantes na sociedade. A escola é uma instituição incorporativa das relações de dominação. Esta incorporação se estabelece por meio do currículo escolar e da ação dos seus profissionais em educação, das famílias e, mais recentemente, dos meios de comunicação de massa e da internet. Para caminharmos na direção da emancipação humana, temos de mapear essas influências e construir projetos educacionais e práticas pedagógicas opositores a esse modo de ser e de viver.

A noção de subjetividade humana, constituída pela indissociabilidade entre o homem econômico, o homem político e o homem estético, fornece elementos para que superemos uma visão dicotômica, ainda predominante entre inúmeros educadores, de uma educação escolar para o trabalho e uma educação para a vida, propiciando a oportunidade de traduzir, na análise científica e na prática educacional e pedagógica, a concepção materialista dialética de trabalho como criação humana nas suas dimensões técnica, ética e estética.

Por fim, como educadores, militantes e acadêmicos que ressaltam a experiência vivida e os condicionantes estruturais da segunda metade do século $\mathrm{XX}$, Thompson e Williams estiveram atentos para a dimensão política do emprego das novas tecnologias de comunicação como práticas culturais. Eles, com suas observações, como Marx em relação à maquinaria, reproduzem no século XXI, a observação marxiana de que a máquina não é boa nem má em si mesma. Eles recomendam, entretanto, atenção ao sentido filosófico, político, estético e educacional do seu uso. Até o momento, majoritariamente, as tecnologias de informação e comunicação, as TICS, vêm sendo utilizadas para difundir, em diferentes linguagens, a cultura hegemônica. Faz-se urgente, numa proposta contrahegemônica de educação política e escolar, a redefinição de seu uso, atualizando a diretriz pedagógica da escola unitária de Gramsci, de modo que as TICS contribuam para que o homem do século XXI seja capaz de pensar, estudar, dirigir e controlar quem dirige.

\section{Referências}

CEVASCO, Maria Elisa. Para ler Raymond Williams. São Paulo: Paz e Terra, 2001.

COUTINHO, Carlos Nelson. O leitor de Gramsci: escritos escolhidos 1916-1935. Rio de Janeiro: Civilização Brasileira, 2011. 
GRAMSCI, Antonio. Cadernos do cárcere. v. 1. Rio de Janeiro: Civilização Brasileira, 1999.

. Cadernos do cárcere. v. 2. Rio de Janeiro: Civilização Brasileira, 2000a.

Cadernos do cárcere. v. 3. Rio de Janeiro: Civilização Brasileira, 2000b.

Cadernos do cárcere. v. 5. Rio de Janeiro: Civilização Brasileira, 2002a.

Cadernos do cárcere. v. 6. Rio de Janeiro: Civilização Brasileira, 2002b.

HOBSBAWM, Eric. Como mudar o mundo. São Paulo: Companhia das Letras, 2011.

MATTOS, Marcelo Badaró. E.P. Thompson e a tradição de crítica ativa do materialismo histórico. Rio de Janeiro: Editora UFRJ, 2012.

THOMPSON, E. P. A Miséria da Teoria ou um planetário de erros: uma crítica ao pensamento de Althusser. Rio de Janeiro: Zahar, 1981.

Costumes em comum. São Paulo: Companhia das Letras, 1998.

. As peculiaridades dos ingleses e outros artigos. Campinas, São Paulo: Editora da Unicamp, 2001.

. Os românticos: a Inglaterra na era revolucionária. Rio de Janeiro: Civilização Brasileira, 2002.

. Formação da classe operária inglesa. v. 1. Rio de Janeiro: Paz e Terra, 2004.

WILLIAMS, Raymond. Marxismo e literatura. Rio de Janeiro: Zahar, 1979.

2007.

Palavras-chave: um vocabulário de cultura e sociedade. São Paulo: Boitempo,

Cultura. Rio de Janeiro: Paz e Terra, 2008.

Cultura e materialismo. São Paulo: Editora Unesp, 2011.

Recebido em janeiro-13

Aprovado em maio-13

Notas

${ }^{1}$ Gramsci, Thompson e Williams questionaram, sobretudo, a interpretação stalinista do marxismo. Gramsci, por intermédio da obra de Bukharin, A teoria do materialismo histórico. Manual popular de sociologia marxista, publicado em Moscou, em 1921; Thompson, por meio da crítica ao marxismo althusseriano; e Williams, por intemédio da crítica às posições do Partido Comunista Inglês na década de 1950.

${ }^{2}$ Gramsci foi preso pelo regime fascista em 1926. Em 1929, quando estava na prisão de Turi, na província de Bari, na Itália, recebeu autorização para receber material para escrever. Desde então até abril de 1935, Gramsci escreveu em 33 cadernos escolares, quatro deles com tradução do alemão e do inglês de autores como: Marx, Goethe e os irmãos Grimm, além de artigos de revistas. Este trabalho se efetivou de 1929 a 1932. A partir de 1932, ele começou a redigir as suas reflexões, que se tornaram conhecidas como os Cadernos do cárcere. Somente em 1948, o conteúdo dos Cadernos do cárcere começou a ser publicado, sob a responsabilidade de Togliatti, por meio da editora Einaudi, com a seguinte sequência temática: $O$ materialismo histórico e a filosofia de Benedetto Croce (1948), Os intelectuais e a organização da cultura (1949), O Risorgimento (1949), Notas sobre Maquiavel, a política e o Estado moderno (1949), Literatura e vida nacional (1950) e Passado e presente (1951). No Brasil, a obra de Gramsci começa a ser publicada em 1966, pela Editora Civilização Brasileira. Naquele ano, a editora publica Concepção dialética da história e cartas do cárcere, em 1968 são publicados os seguintes títulos: Os intelectuais e a organização da cultura; Literatura e vida nacional; Maquiavel, a política e o Estado moderno. Em 1975, é publicada, na Itália, por 
Valentino Getarrana, uma edição completa dos Cadernos. No Brasil, a edição completa dos Cadernos do cárcere começou a ser publicada em 1999, por iniciativa de Carlos Nelson Coutinho.

${ }^{3}$ A partir da segunda metade da década de 1950, intelectuais oriundos de diferentes correntes de esquerda, inclusive um grupo que militava no Partido Comunista da Grã-Bretanha, ao tomarem conhecimento das atrocidades cometidas pelo governo de Stalin, fizeram profundas críticas à interpretação dogmática e reducionista do pensamento marxista, inclusive alguns romperam com o Partido, como: Edward P. Thompson, Raymond Williams e Richard Hoggar. Eles participaram de um movimento denominado "Nova Esquerda".

${ }^{4}$ Coutinho (2011, p. 15) registra que desde seus primeiros escritos “o jovem intelectual sardo já atribuía grande importância à batalha das ideias, à luta cultural, ou seja, ao empenho para criar as condições objetivas da ação revolucionária, rompendo assim com a passividade dos que confiavam apenas no amadurecimento espontâneo das condições objetivas". Cultura está presente em todos os volumes dos Cadernos do cárcere, sua obra de maturidade. A palavra aparece nesses volumes aproximadamente oitocentas vezes. Nos seus vários projetos para os Cadernos, os temas culturais se destacaram. No primeiro plano de trabalho, de 1927, Gramsci pretendia estudar, por exemplo, os intelectuais italianos, o teatro de Pirandello, os romances de folhetim e o gosto popular na literatura, além de temas de linguística. Em 1929, em carta para Tatiana Schucht, Gramsci reforça a ideia de estudar os intelectuais italianos e acrescenta a temática do americanismo e fordismo. Neste mesmo ano, já no primeiro caderno, elenca dezesseis temas do seu interesse de estudo, dos quais 50\% referentes a temas de cultura. Novamente aparecem a temática dos intelectuais, a literatura popular dos romances de folhetim e americanismo e fordismo. São incluídos ainda: os tipos de revistas, o conceito de folclore, a questão da língua na Itália, além de temas específicos sobre a Divina comédia e linguística. No caderno 8, de 1931, aparecem também como pontos a aprofundar entre os temas culturais: a escola e a educação nacional; a escola única e seu significado para a organização da cultura nacional; o teatro italiano e o jornalismo (Gramsci, 1999).

${ }^{5}$ Para maiores esclarecimentos sobre as mudanças culturais a que Williams se reporta, ver Eric Hobsbawm, Era dos Extremos, capítulo 11, “A Revolução Cultural”, p. 314-336. O livro de Marcos Dantas, intitulado A lógica do capital-informação, publicado pela Contraponto, em 2002, também traz informações interessantes sobre as novas tecnologias utilizadas em nosso país a partir da década de 1980.

${ }^{6}$ Embora reconheça que, na atualidade, a noção de cultura inclua ainda o sentido original de cultivo agrícola, observa que, no sentido moderno, cultura pode ser: "um substantivo independente abstrato que descreve um processo de desenvolvimento intelectual, espiritual e estético"; "um substantivo independente", que designa "um modo particular de vida, quer seja de um povo, um período, um grupo ou da humanidade em geral"; e um "substantivo independente e abstrato que descreve as obras e as práticas da atividade intelectual e artística” (WILLIAMS, 2007, p. 121).

${ }^{7}$ Gramsci afirmava que o Estado deve ser concebido como 'educador' na medida em que tende precisamente a criar um novo tipo ou nível de civilização. E observou: todo Estado é ético e de cultura "na medida em que uma das suas funções mais importantes é elevar a grande massa da população a um nível cultural e moral, nível (ou tipo) que corresponde às necessidades de desenvolvimento das forças produtivas e, portanto, aos interesses dominantes" (GRAMSCI, 2000b, p. 284).

${ }^{8}$ Vale realçar que Gramsci não conheceu o avassalador alcance do papel educador da televisão, embora já estivesse atento para o caráter educativo dos jornais e revistas nos anos iniciais do século XX.

${ }^{9}$ O projeto educacional liberal do capitalismo do século XX rompe com o dualismo educacional existente até seus anos iniciais, criando uma escola única, a escola básica, mantendo o conceito de trabalho como atividade profissional, que prescinde da unidade teórico-prática da atividade humana, pressuposto fundamental da escola gramsciana. $\mathrm{Na}$ atualidade, a educação escolar, embora formalmente garanta a igualdade de oportunidades, introduz, na prática, barreiras intransponíveis na sua estruturação, impedindo que parte substancial das massas trabalhadoras possa exercer autonomamente a sua humanidade.

${ }^{10}$ Parece que este comentário ainda se aplica à realidade brasileira na primeira década do século XXI.

${ }^{11}$ Sua proposta difere da privatização da educação e da cultura própria da lógica capitalista neoliberal da atualidade. Williams tinha clareza de que o Estado de classe selecionaria as iniciativas culturais de modo a majoritariamente reproduzir a hegemonia dos dominantes. O controle da sociedade consistiria em um processo coletivo de tomadas de decisões, onde interesses individuais e grupistas não se impusessem a demandas de fato universais. 